\title{
Production Process Evaluation of a Job Shop Fabrication Line - A Case Study at a Door Manufacturer
}

\author{
Elia Oey ${ }^{\mathrm{a}}$, Albert Brilliant Limita ${ }^{\mathrm{b}}$, Harold Adhitjan $^{\mathrm{b}}$ \\ International Business Management, Business School, Bina Nusantara University, Tangerang, Indonesia \\ aeliaoey@binus.ac.id, balbertlimita.al@gmail.com, "charold201@yahoo.com
}

\begin{abstract}
With the increasing market competitiveness, it is crucial for company to remain effective and efficient in its Operation Management. Production process is one of major areas where company seeks to improve its production capability in order to remain competitive. The research was a case study in a door fabrication line. The production process is a job shop process type which consists of several inter-linked and inter-dependent sub-processes with shared resources. The study used simulation methodology and Simio software to better understand and analyze the complexity of the process. The study fed few controlled and uncontrolled input variables into the simulation models and analyzed on how to improve some output/response variables. Six scenarios were analyzed during experimentation leading to the best scenario 7 giving improvement in term of crew utilization, average time, and number of entity in the system. Besides giving recommendations to the studied company, the study also successfully demonstrated on how simulation can be used to mimic different kinds of process logic in a job shop production process.
\end{abstract}

Keywords: Discrete Event Simulation, Simio, Fabrication Line, Job Shop.

\section{Introduction}

As the 4th largest country in the world with population over than 250 million people, property is one of the most popular investment types in Indonesia. Indonesia market demand in property sector is substantial and expected to keep growing in the coming years. Data from [1] showed that Indonesia's spending per capita on housing is $25 \%$ of total GDP, indicating property as an important sector (see Figure 1).

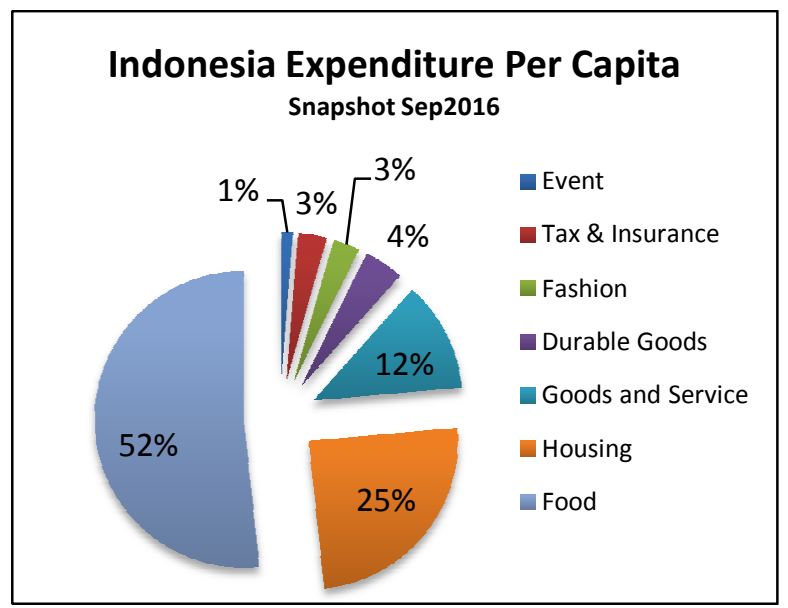

Figure 1. Indonesia expenditure per capita

This can be seen clearly with the widespread developments of both landed and high rise housing residential. Figure 2 shows the market size and growth of property sector in Jakarta area for the last 6 years and future prediction. Despite declining trends in the recent years, property sector still perceived as a potential market segment as homebuyers use the products for both direct commercial usage and investment. This potential market size and growth in property sector also creates "trickles-down" effect to other constructionsupporting industries such as door manufacture.

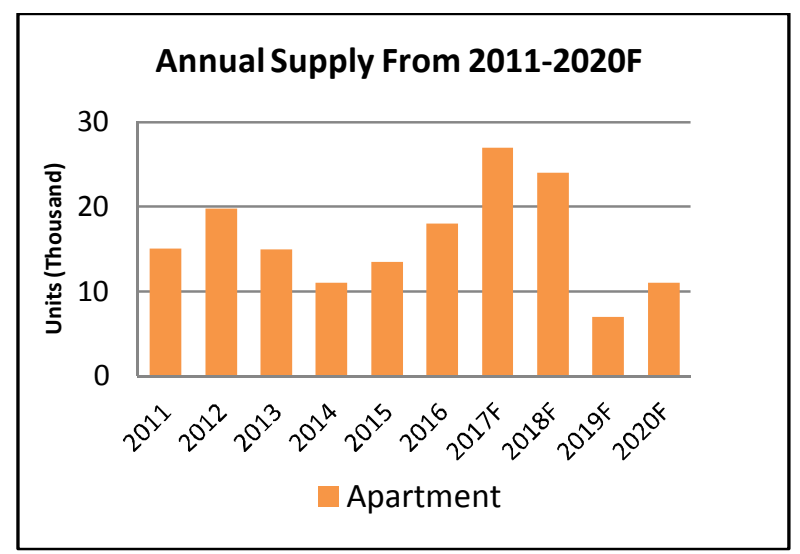

Figure 2. Annual apartment supply from 2011 to 2020F [2]

The research is a case study in a fabrication line of a door manufacturer located in East Jakarta. The studied company produces and sells both door leaves and frames to major developers in the greater Jakarta region. The studied process is a job shop production set-up where variety of products must be processed through sequence of sub-processes with shared and limited resources. The objective of the research is to evaluate the current performance of the studied fabrication line, to analyze on how to improve the current process, and to recommend some improvements to the studied company. 
Production process is the activities of transforming materials and information into goods that satisfy customer needs. The main essence of production process is to add value to the material through the transformation of inputs to outputs [3].

Constant efforts have been made to optimize any production processes. Nevertheless, challenges and thus potential improvement in production process to some extend depends on its process type. Heizer \& Render [3] suggested four types of process strategy commonly used in production process as depicted in Figure 3.

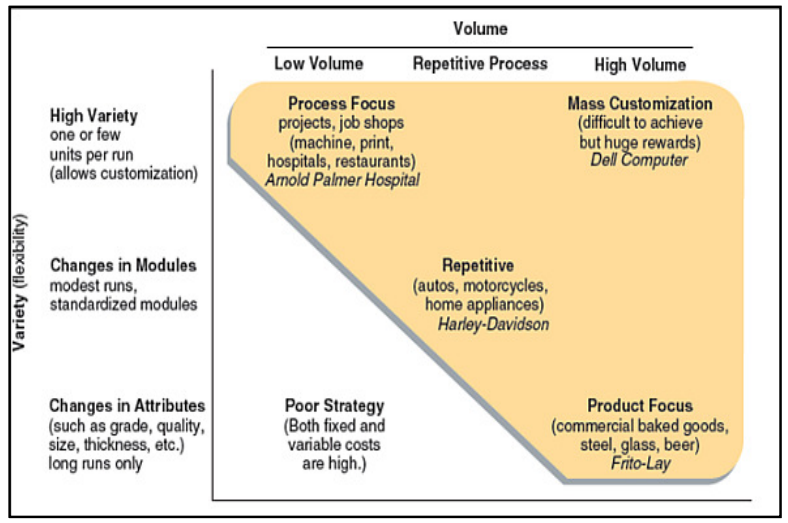

Figure 3. Types of production process [3]

The studied production process can be considered as fabrication line, which is a manufacturing system that features a series of processing steps. At each step, an operation is performed that makes items closer to becoming a finished product. At the same time, it is also a job-shop process, where product varies, volume is slightly low, and each product type has different routing sequence along the processes [3].

The most common way to improve a production process is by performing a line balancing across the whole sub-processes along the line. Line balancing is a method to improve assembly line efficiency with the aim of achieving the highest level of production and / or shortest path. The main objective of line balancing is to align the processing time of each sub-process such that it will minimize the time of the machines and the operators [4]. A balanced line will ultimately give the least total time in system and higher throughput.

As production lines become longer and sequences become more complex such as in a job-shop environment, line balancing task is not simple and can become overwhelming. For this kind of environment, the main objective is then to directly maximize throughput and minimize time in system.

The common challenge in job shop environment is in its scheduling task, leading to extensive research for the last six decades. In a job shop environment, each job requires several steps to be done on various machines. The objective in a job shop is then to run production that will give the best production performance [5]. Other studies in job shop environment deal with identifying the bottleneck, determining the best schedule that optimizes resource utilization and throughput by changing product mix or resource allocation [6].

One of the tools that can help to overcome the complexity in this job-shop production type is through the use of discrete event simulation. Simulation is an excellent problem-solving methodology for the solution of many real-world problems. Simulation is typically used to describe and analyze the behavior of a system, ask "what if" questions about the real system, and aid in the design of real systems. Both existing and conceptual systems can be modeled with simulation [7].

There are different classification types of simulation [7], namely: (1) Static or dynamic, (2) Deterministic or stochastic, or (3) Discrete or continuous.

The static simulation model represents a system at a given time. One of the most common types of static simulations is by using random numbers to solve problems, usually stochastic, but time rolling has no role. Dynamic Simulation is a study to know information-feedback characteristics to tell how organization structure, amplification, and time delay in decision and action model communicate to give impact to the success of the company [8].

The deterministic simulation model assumes no variability in the model parameters and, therefore, does not involve random variables. A deterministic model will give the same value as snapshot model performance of a given time. Stochastic simulation model uses one or several random variables to better model the processes in the system observed. The output of the stochastic simulation model is random and therefore only an estimate of the actual characteristics of the model.

Continuous simulation model is where variable conditions change continuously, for example, fluid flow in pipes or the flight of an aircraft, where the conditions of position and velocity variables change continuously with each other. Discrete simulation model is where variable conditions change only at some point in time. In addition, discrete simulation is recommended in queuing problems and complicated queuing systems scenarios [8].

The use of simulations continues to increase due to the inability and complexity of the manual analysis in solving the increasingly complex problems. Many managers have realized the ease of utilizing simulations in analyzing a problem. Using simulation, real-life random behavior can be modelled through properly identifying probability distributions taken from historical data, for example, random arrivals and random arrival numbers. Simulation also gives flexibility to find the best operation condition without interrupting the current system [9]. The application of simulation varies from performance evaluation of existing system to designing a new one [10], or to find ways to increase productivity [11], or even exploring worker flexibility [12]. Table 1 summarizes the advantages and disadvantages of simulation [7].

Most of the manufacturing systems are modeled as simulated dynamic, discrete, stochastic, and events 
Table 1. Advantages and disadvantages of simulation (adapted from [7])

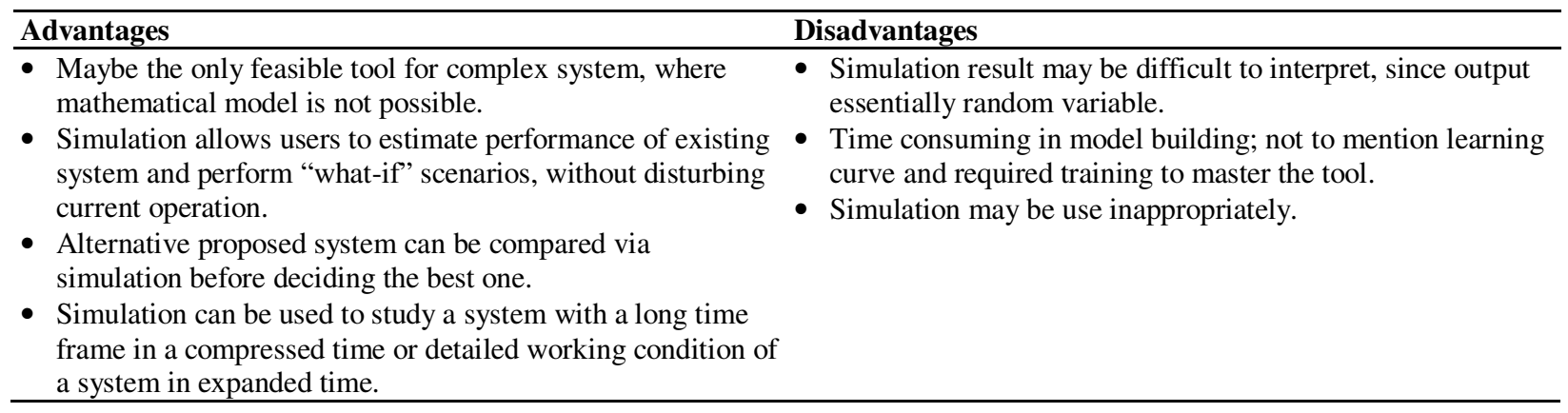

Table 2. Typical simulation application in manufacturing system [13]

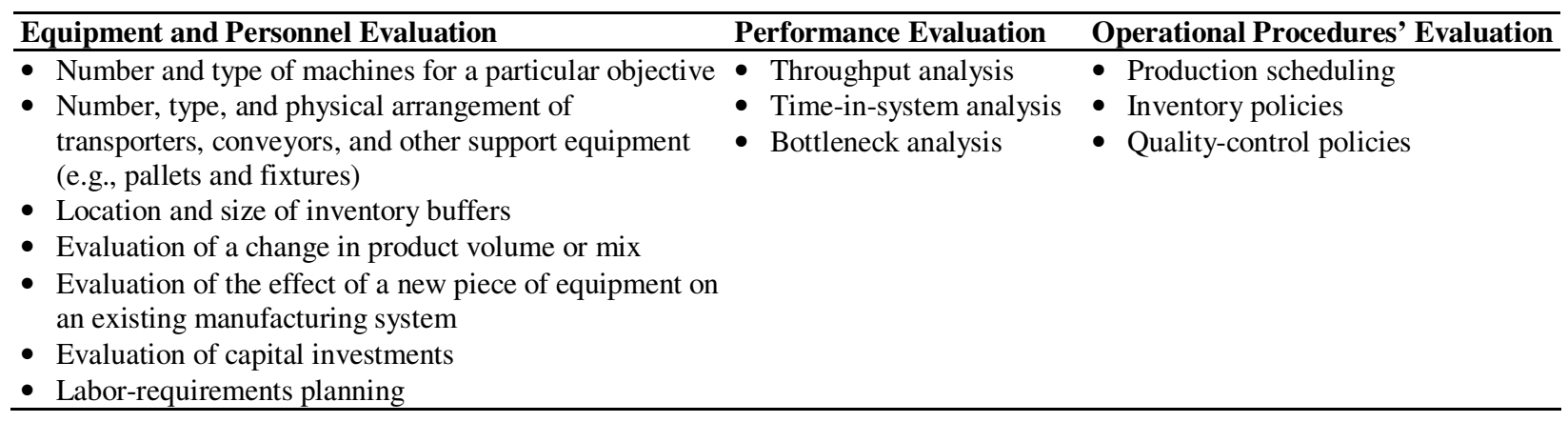

using random variables to model arrival ranges, queues, processes, etc. Table 2 summarizes typical problems in manufacturing that are typically handled with simulation methods. Simulation of manufacturing system typically evaluates common performance measure such as process throughput, time in system for parts, times parts spend in queues, queue sizes, timeliness of deliveries, or utilization of equipment or personnel [13].

\section{Research Methods}

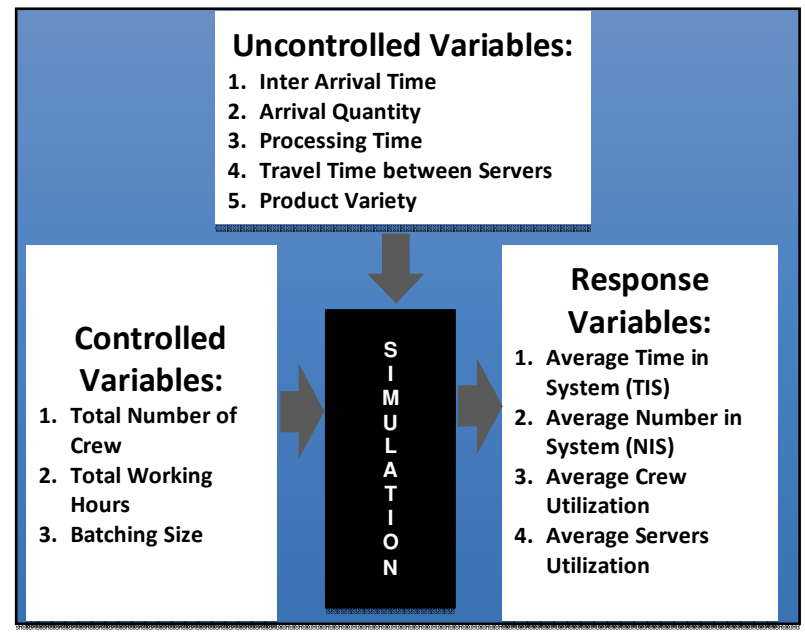

Figure 4. Operational variables

During the simulation study, the following variables were used in order to calculate and analyze the studied fabrication line (see Figure 4):
- Controlled variables, which are input variables that can be altered in order to get a better performance of the overall system. Number of Crew $1 \& 2$, Total Working Hours, and Batching Size were the controlled variables used in this study.

- Uncontrolled variables, which are also input variables to the system under study, but they are uncontrollable. In the studied fabrication line, Inter Arrival Time, Arrival Quantity, Processing Time, Travel Time between Servers, as well as Product Variety belonged to this group.

- Response variables, which are basically output variables expected from the study. The response variables captured from this simulation studies were Average Time in System, Average Number (of Part) in System, Average Crew Utilization, and Average Servers Utilization.

Most of processing times used in the simulation model were determined through time motion study. For each of the processes, 30 observations were first measured. The results were then re-checked using the following formula to make sure that the number of observation was sufficient.

$$
N^{\prime}=\left[\frac{\frac{k}{s} \sqrt{N \sum X_{i}^{2}-\left(\sum X_{i}\right)^{2}}}{\sum X_{i}}\right]^{2}
$$

where:

$N^{\prime}$ : Total data observations that need to be collected

$N$ : Total data observations already collected $=30$

$k$ : Level of confidence $(95 \%, k=1.96 \approx 2)$

$s$ : Degree of accuracy $(90 \%, s=10 \%)$ 
If $N^{\prime} \leq N$, the number of observations was adequate. If $N^{\prime} \geq N$, more data observations need to be done [14].

After time motion study was completed, the observed data were then fitted into certain random distributions through Goodness-of-Fit-Test. The goodness-of-Fit-Test basically tests the following hypotheses:

$\mathrm{H}_{0}$ : The random variable $X$ conforms to the distributional assumption with parameter(s) given by the parameter estimate(s).

$\mathrm{H}_{1}$ : The random variable $X$ does not conform.

The test was done either by Chi-Square or Kolmogorov-Smirnov test using Arena Input Analyzer. Arena Input Analyzer is an add-on application provided by Arena simulation software to perform distribution fitting. The software can give result of distribution fitting using both Chi-Square and KolmogorovSmirnov test, whichever more suitable. For small sample size data, it automatically does the distribution fitting using K-S test, as Chi-square is not suitable [15].

With the Arena Input Analyzer, the resulted $p$ values were compared with the $\alpha=0.05$. If the resulted $p$ value $\leq \alpha$, then the tested random distribution is a good fit with confidence of $1-\alpha$. Else, it should be rejected.

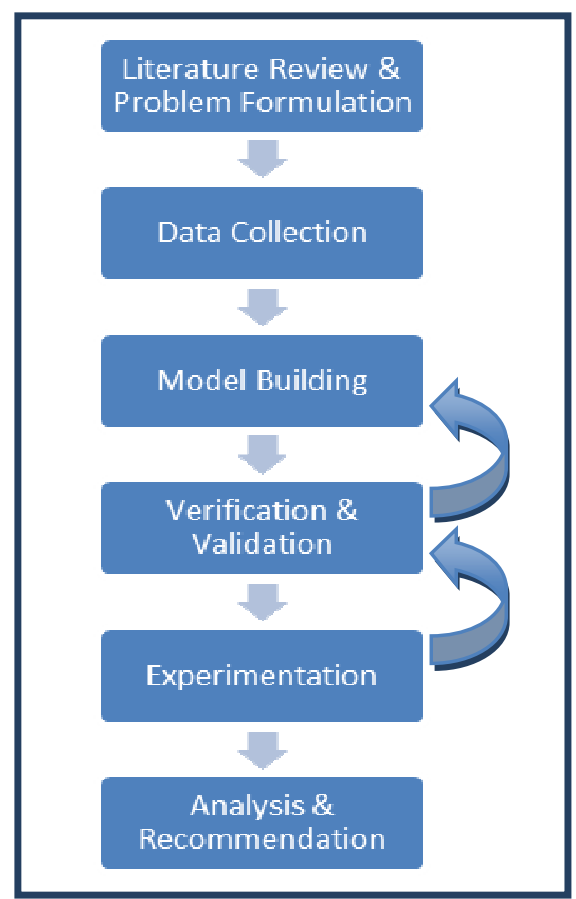

Figure 5. Proposed framework (adapted from [16])

The overall steps performed during simulation study are illustrated in Figure 5, as adapted from [16] with the following elaboration:

(1) Problem Formulation: In this step, preliminary assessment was done to make sure a clear understanding of the problem was attained. This was done through interview with few key personnel of the studied company, enriched with direct observations to the fabrication site. The deliverables of this stage are a rough idea on what to be included in the model and preliminary indicators to be measured and simulated.

(2) Literature Review: Parallel with problem formulation, literature review was also performed. The purpose is to gain insights what variables are typically needed in a simulation study of a production system such that belonging to the studied company. Literature review on Simio capability was also conducted as learning mechanism in using Simio while building the required model.

(3) Data Collection: Table 3 summarizes data that were collected during the study for processing time of each sub-process. For sub-processes where variations are considered significant, time motion study was performed in order to fit the data into certain random distribution. For sub-processes which are considered more or less constant, a constant processing time based on interview was used.

Table 3. Types and sources of data

\begin{tabular}{lll}
\hline \multicolumn{1}{c}{ Data } & \multicolumn{1}{c}{ Type } & \multicolumn{1}{c}{ Method } \\
\hline $\begin{array}{l}\text { Inter-arrival and } \\
\text { quantity of order }\end{array}$ & \multirow{2}{*}{ Secondary Data } & $\begin{array}{l}\text { Documentation } \\
\text { Study }\end{array}$ \\
\hline $\begin{array}{l}\text { Production process } \\
\text { flow and parameters }\end{array}$ & Primary Data & $\begin{array}{l}\text { Interview and } \\
\text { Observation }\end{array}$ \\
$\begin{array}{lll}\text { Processing time for } \\
\text { each processes }\end{array}$ & \multirow{2}{*}{ Primary Data } & $\begin{array}{l}\text { Time \& Motion } \\
\text { Study and Interview }\end{array}$ \\
\hline
\end{tabular}

(4) Model Building: After data were collected, the next step was to convert them into a simulation model. Simio software is equipped with some small examples called Simbits, some of which were adopted to make the intended model and smoothen the learning curve in model building.

(5) Verification \& Validation: Verification is the examination of whether the computer simulation program runs as per what is desired. By contrast, validation is the determination of whether the conceptual simulation model is an accurate representation of the real system being modeled. The verification and validation were done against the base model, which represented the current situation of production process of the studied company. However, due to lack of historical data, only a simple validation was performed by confirming the results of output parameters from the base model with key production staffs of the studied company.

(6) Experimentation: Once the base model was created, verified, and validated, the next step was to create some experimentation. Experimentation is basically creating alternatives/scenarios by changing some of the controlled input variables in order to improve the current / base model. Model Building $\Rightarrow$ Verification \& Validation $\Rightarrow$ Experimentation were done iteratively, as improvement was made in stages as learning curve was accrued. During the experimentation, 
simulation run length and number of replication per each scenario were also determined.

(7) Analysis and Recommendation: Once sufficient experimentation was done, the final step was to analyze the result and give recommendation for system improvement.

This study used Simio Simulation and Scheduling Software, created by Simio LLC, for building the model. Simio adopts an object-based approach into the software, making its application varies, such as for designing queuing strategy to improving customer satisfaction [17], or testing a procedure in a port logistic system [18], or computing production line energy consumption [19]. With Simio, users can select building blocks from libraries and graphically place them in the model by simple drag-and-drop actions. Each building block represents a physical component in a typical system such as server, workstation, conveyor, worker, or forklift truck in a manufacturing facility. Table 4 lists a few of Simio building blocks that were used in this study. Simio is also enhanced with add-on processes making tailored process logic possible.

Table 4. List of used Simio building blocks [20]

\begin{tabular}{|c|c|}
\hline $\begin{array}{l}\text { Building } \\
\text { Block }\end{array}$ & Explanation \\
\hline Source & $\begin{array}{l}\text { Used to model the arrival of entity to the } \\
\text { simulation model. Random variables of } \\
\text { orders' inter arrival time and quantity can } \\
\text { be modeled here. }\end{array}$ \\
\hline Sink & $\begin{array}{l}\text { Represent the last process of the model. } \\
\text { Typically all the statistics and reports of } \\
\text { the model are captured here. }\end{array}$ \\
\hline Server & $\begin{array}{l}\text { Represent the simplest form of operation, } \\
\text { where entity is being processed with } \\
\text { possibility to model input and output } \\
\text { buffer. }\end{array}$ \\
\hline arator & $\begin{array}{l}\text { Used to model processes which need to } \\
\text { split each entity into batches from parent } \\
\text { entities, copy entities, or even create new } \\
\text { entities. }\end{array}$ \\
\hline Combiner & $\begin{array}{l}\text { Used to combine the entities into a batch } \\
\text { and process it as one entity. }\end{array}$ \\
\hline & $\begin{array}{l}\text { Used as moveable resources that are seized } \\
\text { and released for task using model process } \\
\text { logic. }\end{array}$ \\
\hline (1) TimePath & $\begin{array}{l}\text { Used to connect each building block with } \\
\text { the setup travel time. }\end{array}$ \\
\hline$\square$ Connector & $\begin{array}{l}\text { Have the same functionality time path, but } \\
\text { without traveling time. }\end{array}$ \\
\hline & $\begin{array}{l}\text { Represent processed parts in the model, } \\
\text { each of which can be named based on type, } \\
\text { sequence, and processing time. }\end{array}$ \\
\hline
\end{tabular}

\section{Result and Discussion}

The production process of the studied company consists of two fabrication lines: Door Leaf (DL) and Door Frame (DF) fabrication line. Both lines shares few of sub-processes and crews. There are 2 crews, namely crew 1 who are in charge for cutting-related processes, while crew 2 are responsible for the remaining of the processes. In summary, it's a job-shop system consists of 2 main intertwined fabrication lines processing 9 product variety. Figure 6 illustrates the overall flow of the 2 fabrication lines of the studied company.

For Door Leaf, there are 9 product types modeled into the system with percentage of occurrences indicated in Table 5. The variety is the combination of core and ornament type, each of which mandate different route or processing time. For Door Frame, each order will consist of 3 components, namely DF stopper, DF Architrave, and DF Body, which need to be combined once their processes completed prior to shipping.

Table 5. Product variety percentage based on core and ornament types

\begin{tabular}{|c|c|c|c|c|}
\hline $\begin{array}{l}\text { Core } \\
\text { Type }\end{array}$ & $\begin{array}{c}\text { \% Core } \\
\text { Type }\end{array}$ & $\begin{array}{c}\text { Ornament } \\
\text { Type }\end{array}$ & $\begin{array}{l}\text { \% Orna- } \\
\text { ment Type }\end{array}$ & $\%$ \\
\hline \multirow{3}{*}{ Empty } & \multirow{3}{*}{$6 \%$} & Nat+ or SS & $26 \%$ & $2 \%$ \\
\hline & & Nat & $62 \%$ & $4 \%$ \\
\hline & & Polos & $12 \%$ & $1 \%$ \\
\hline \multirow{3}{*}{$\mathrm{FC}$} & \multirow{3}{*}{$7 \%$} & Nat+ or SS & $26 \%$ & $2 \%$ \\
\hline & & Nat & $62 \%$ & $4 \%$ \\
\hline & & Polos & $12 \%$ & $1 \%$ \\
\hline \multirow{3}{*}{$\mathrm{HC}$} & \multirow{3}{*}{$87 \%$} & Nat+ or SS & $26 \%$ & $22 \%$ \\
\hline & & Nat & $62 \%$ & $54 \%$ \\
\hline & & Polos & $12 \%$ & $10 \%$ \\
\hline & \multicolumn{2}{|c|}{ Total } & & $100 \%$ \\
\hline
\end{tabular}

There are 9 machines in the model, few of which shared by both DF and DL fabrication lines. Table 6 gives overview of machine and crew capacity.

Table 6. Resources capacity

\begin{tabular}{lcc}
\hline \multicolumn{1}{c}{ Resource Name } & $\begin{array}{c}\text { Available } \\
\text { Quantity }\end{array}$ & Fab. Area \\
\hline Cutting Machine & 2 & DL \& DF \\
Angle Cutting Machine & 1 & DF \\
Big Pressing Machine & 1 & DL \\
Manual Pressing Machine & 1 & DF \\
Big Cutting Machine (Edging) & 2 & DL \\
Molding Machine & 1 & DF \\
Carving Machine & 2 & DL \\
Carousel Painting Machine & 1 & DL \\
Auto Painting Machine & 1 & DF \\
\hline Crew 1 & 3 & DL \& DF \\
Crew 2 & 25 & DL \& DF \\
\hline
\end{tabular}

Other input parameters are "Inter-arrival time" and "Order Quantity" of both DL and DF which were taken from historical data and fitted into random distribution using Arena Input Analyzer software. The result of the distribution fitting of inter-arrival and order quantity is summarized in Table 7.

Processing time for each sub-processes were calculated by conducting time and motion study with sample of 30 per each sub-processes. Theoretical sample sizes per each process are also rechecked using equation (1) in previous sub-section. If the calculated sample size $>30$, then few more added to comply with equation (1). Summary of calculated sample size is summarized in the last column of Table 8. 


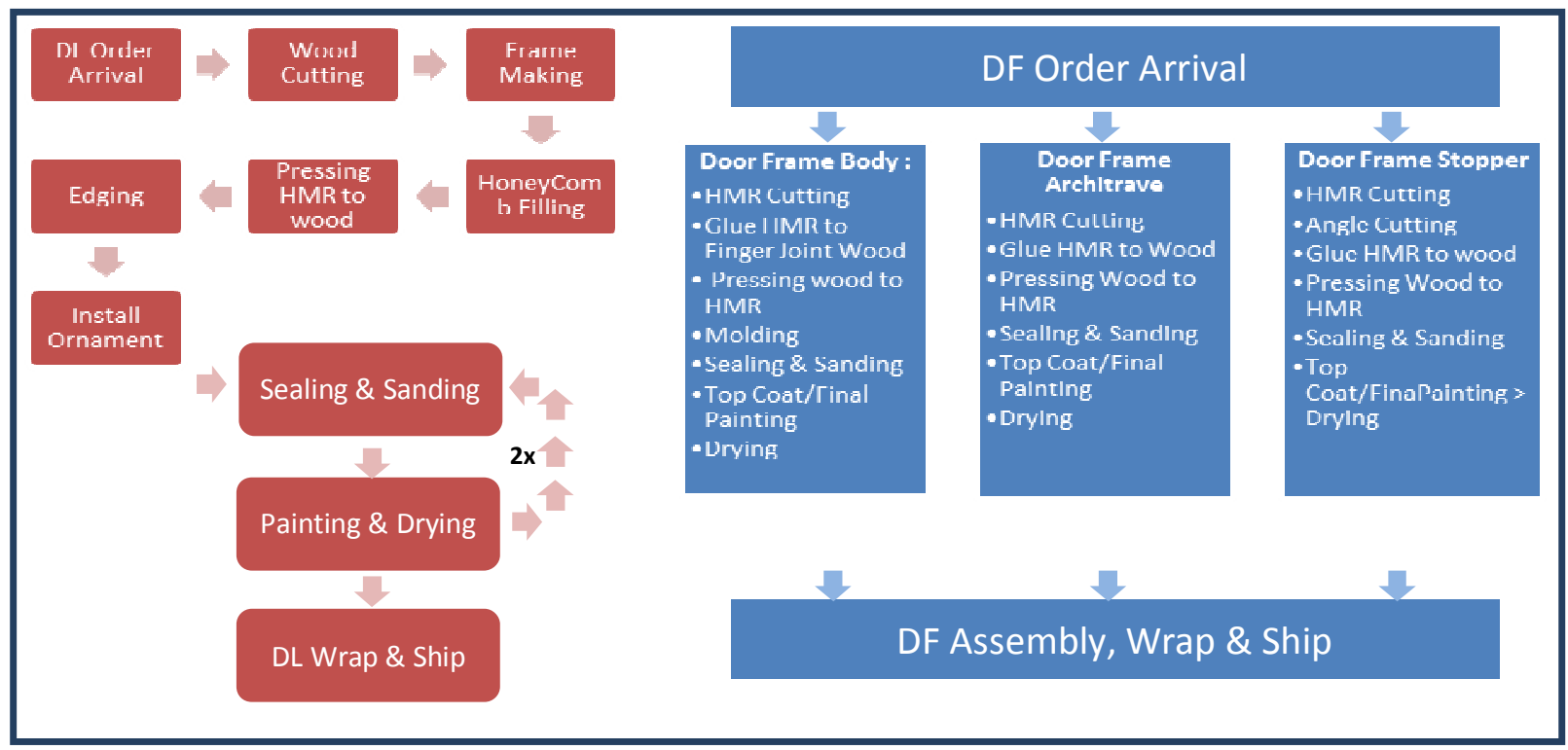

Figure 6. Overview of production process

Table 7. Inter-arrival and order quantity details

\begin{tabular}{|c|c|c|c|}
\hline Input Variables & Result of Goodness-of-Fit-Test & Input Variables & Result of Goodness-of-Fit-Test \\
\hline $\begin{array}{l}\text { "Order Quantity" } \\
\text { Door Leaf }\end{array}$ & $\begin{array}{l}\text { Distribution: Weibull } \\
\text { Expression: } 0.999+\mathrm{WEIB}(21.8,0.647) \\
\text { Square Error : } 0.002467\end{array}$ & $\begin{array}{l}\text { "Inter-arrival time" } \\
\text { Door Leaf }\end{array}$ & $\begin{array}{l}\text { Distribution: Beta } \\
\text { Expression: } 0.5+18 * \operatorname{BETA}(0.653,5.16) \\
\text { Square Error : } 0.001854\end{array}$ \\
\hline $\begin{array}{l}\text { "Order Quantity" } \\
\text { Door Frame }\end{array}$ & $\begin{array}{l}\text { Distribution: Weibull } \\
\text { Expression: } 0.999+\text { WEIB }(10.8,0.701) \\
\text { Square Error : } 0.005601\end{array}$ & $\begin{array}{l}\text { "Inter-arrival time" } \\
\text { Door Frame }\end{array}$ & $\begin{array}{l}\text { Distribution: Beta } \\
\text { Expression: } 0.5+33 * \operatorname{BETA}(0.469,2.63) \\
\text { Square Error : } 0.009136\end{array}$ \\
\hline
\end{tabular}

Table 8. Summary of distribution fitting of sub-processes

\begin{tabular}{|c|c|c|c|}
\hline Work Station & Type & Distribution & Calculated Sample Size \\
\hline \multirow{4}{*}{ Wood Cutting Machine } & All Door Leaf & $6+\operatorname{GAMM}(1.84,1.38)$ & 24 \\
\hline & Body & $\operatorname{TRIA}(4,6,8)$ & 10 \\
\hline & Stopper & $\operatorname{TRIA}(3,4.34,7.45)$ & 13 \\
\hline & Architrave & $3.08+\operatorname{GAMM}(2.74,0.766)$ & 1 \\
\hline Angle Cutting Machine & All Door Frame & 3.14 & - \\
\hline Frame Making & All Door Leaf & $7.33+6.67 * \operatorname{BETA}(0.988,1.06)$ & 13 \\
\hline \multirow{3}{*}{ Honeycomb Filling } & $\mathrm{FC}$ & $12.5+\operatorname{GAMM}(5.48,0.144)$ & 1 \\
\hline & $\mathrm{HC}$ & $8+6 * \operatorname{BETA}(1.66,1.59)$ & 7 \\
\hline & Empty & 0 & - \\
\hline \multirow{4}{*}{ Pressing } & Automatic & 90 & - \\
\hline & Body & 90 & - \\
\hline & Stopper & 90 & - \\
\hline & Architrave & 90 & - \\
\hline Edging & All Door Leaf & 4.49 & - \\
\hline Molding & Body & TRIA $(11,11.9,12.8)$ & 1 \\
\hline \multirow{4}{*}{ Glue } & All Door Leaf & 4.43 & - \\
\hline & Body & 8.83 & - \\
\hline & Stopper & 8.83 & - \\
\hline & Architrave & 8.83 & - \\
\hline \multirow{3}{*}{ Install Ornament } & Nat & NORM $(10.7,0.888)$ & 3 \\
\hline & Stainless & $\operatorname{TRIA}(10,12.5,15)$ & 3 \\
\hline & Empty & 0 & - \\
\hline \multirow{4}{*}{ Sealing and Sanding } & All Door Leaf & $29+47 * \operatorname{BETA}(0.775,0.975)$ & 31 \\
\hline & Body & $40+18 * \operatorname{BETA}(0.923,1.04)$ & 4 \\
\hline & Stopper & $27+12 * \operatorname{BETA}(0.857,1.08)$ & 4 \\
\hline & Architrave & $37+16 * \operatorname{BETA}(0.795,1.01)$ & 4 \\
\hline \multirow{4}{*}{ Painting } & All Door Leaf & TRIA( $7.65,9.83,10.8)$ & 2 \\
\hline & Body & 4.19 & - \\
\hline & Stopper & 4.19 & - \\
\hline & Architrave & 4.19 & - \\
\hline \multirow{2}{*}{ Clean \& Wrapping } & All Door Leaf & $11+\operatorname{WEIB}(2.66,11.5)$ & 14 \\
\hline & All Door Frame & $16+13 * \operatorname{BETA}(0.999,1.05)$ & 11 \\
\hline
\end{tabular}


Table 9. Summary of travel time between servers

\begin{tabular}{llc|llc}
\hline \multicolumn{1}{c}{ From } & \multicolumn{1}{c|}{ Door Leaf Process } & \multicolumn{2}{c}{ Door Frame Process } \\
\hline Warehouse & \multicolumn{1}{c|}{ To } & $\begin{array}{c}\text { Travel Time } \\
\text { (Sec) }\end{array}$ & \multicolumn{1}{c}{ From } & \multicolumn{1}{c}{ To } & $\begin{array}{c}\text { Travel Time } \\
\text { (Sec) }\end{array}$ \\
Wood Cutting & Wood Cutting & 80 & Warehouse & HMR Cutting & 80 \\
Frame Making & HC Filling & 10 & HMR Cutting & Glue & 10 \\
HC Filling & Pressing & 10 & HMR Cutting & Angle Cutting & 45 \\
Pressing & Edging & 10 & Angle Cutting & Glue & 40 \\
Edging & Ornament & 10 & Glue & Pressing & - \\
Ornament & Sealing \& Sanding & 25 & Pressing & Molding & 30 \\
Sealing \& Sanding & Base Painting & 32 & Molding & Sealing \& Sanding & 25 \\
Base Painting & Drying & - & Sealing \& Sanding & Painting & 20 \\
Drying & Sealing \& Sanding & 35 & Painting & Drying & 32 \\
Drying & Cleaning \& Wrapping & 60 & Drying & Wrapping & - \\
Cleaning \& Wrapping & Warehouse & 42 & Wrapping & Warehouse & 35 \\
\hline
\end{tabular}

The processing times from time motion study were then fitted into random distribution with KolmogorovSmirnov test using Arena Input Analyzer, with $\alpha=$ 0.05 . Results of the distribution fitting are summarized in Table 8.

During the production process, there was travel time consumed when an entity travels between servers. These travel times, as summarized in Table 9, were accommodated into the model. However, they were assumed to be deterministic instead of stochastic time.

After all the required data were collected, the model was then built. The model used only some, and not all, Simio building blocks, as listed in Table 4. Despite some simplification, the model used and reflected some of the complexity of the studied fabrication lines. The screenshot of the model is as illustrated in Figure 7.

Once the base model was built, it needed to be verified. Model verification is the process of debugging the model to make sure process flow and logics in the model are as per what are intended. Verification was done throughout and during the stages of model buildings. During the verification process, complexity of the model was reduced in order to make the verification process easier. The following steps are what were done to simplify the verification process:

(1) Temporarily eliminate randomness in the model by making it deterministic, e.g., by changing the random processing time with a constant value during verification.

(2) Run the deterministic model several times to make sure the result is consistent.

(3) Study the generated statistics reports to make sure the result is as per expected.

(4) Use animation and state variable to check whether the entity flows are as per what expected.

Table 10 shows some examples of verification to the base model.

Besides verification, model validation was also needed. Model validation is the process of assessing whether the situation of the actual problem is well captured so that the model developed is the appropriate one. Unfortunately, the studied company was lacking of historical data of the output variables. Therefore, this research only did simplistic validation, i.e., by confirming the resulted average Time in System (TIS) of DF \& DL to the company key production supervisor.

After the base model was verified and validated, some scenarios were experimented. The experiment was done by altering some "input controlled variables" and evaluating their impact on the following "response variables", i.e.: (1) Average time in system for Door Frame (TIS DF), (2) Average time in system for Door Leaf (TIS DL), (3) Average number in system for Door Frame (NIS DF), (4) Average number in system for Door Leaf (NIS DL), (5) Crew utilization for Crew 1 and Crew 2.

Table 10. Summary of verification

\begin{tabular}{l}
\hline Sample of Verifications in the Base Model \\
\hline 1. \\
The combining process of DF subcomponents at \\
the wrapping server was based on attribute \\
"Order Number". \\
\hline 2. \\
The correct number of workers was seized at \\
each process as per intended. \\
\hline 3. $\begin{array}{l}\text { For servers with competing crew, debugging } \\
\text { was also performed to make sure entities did }\end{array}$ \\
wait for available crew. \\
\hline 4. $\begin{array}{l}\text { Some of server processing time used } \\
\text { mathematical expression. Verification was also } \\
\text { performed to make sure the expression was used } \\
\text { correctly. }\end{array}$ \\
\hline 5. The "drying" processing time was set to 24 \\
hours without seizing any workers and ignoring \\
the working time.
\end{tabular}




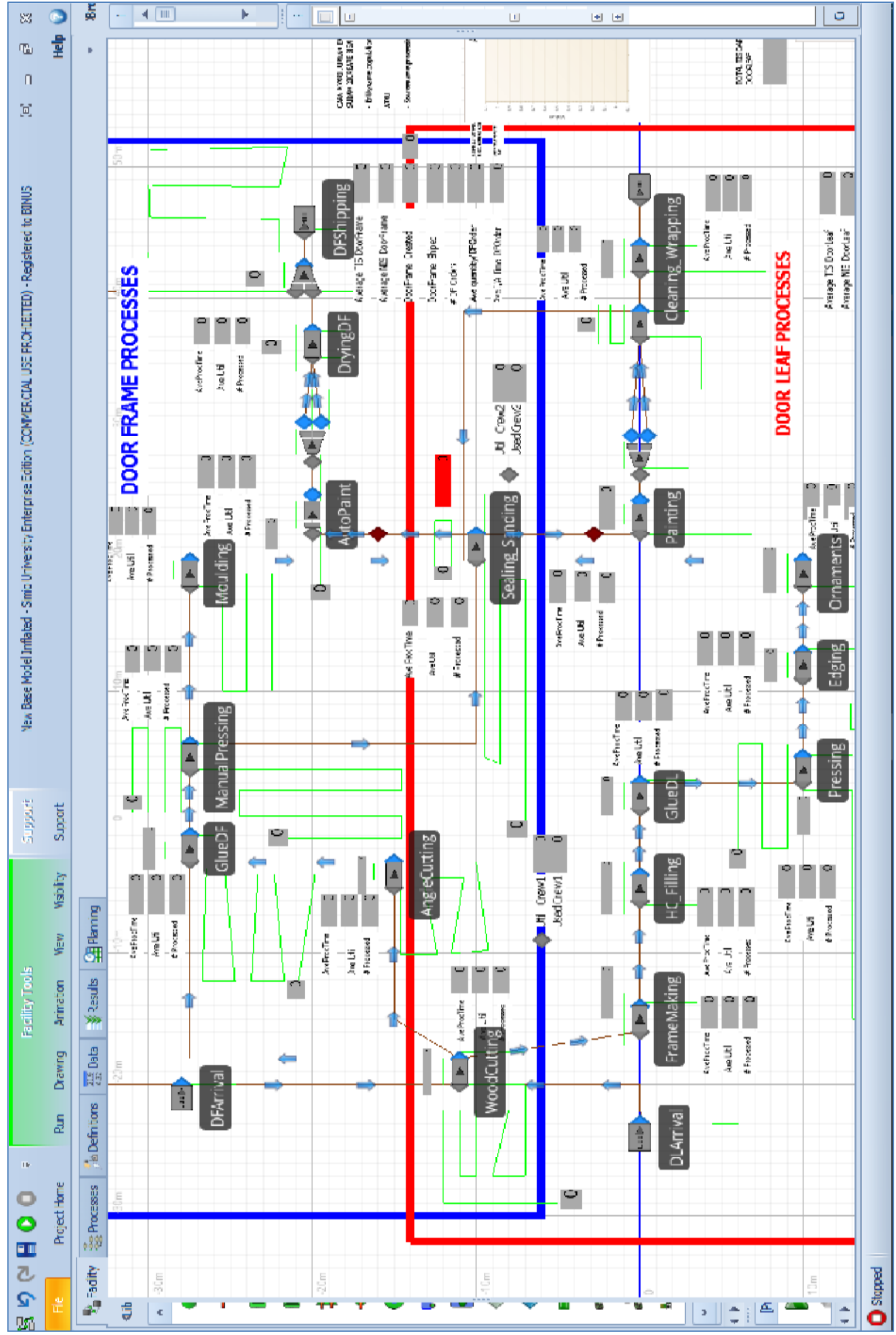

Figure 7. Screenshot of simulation model 


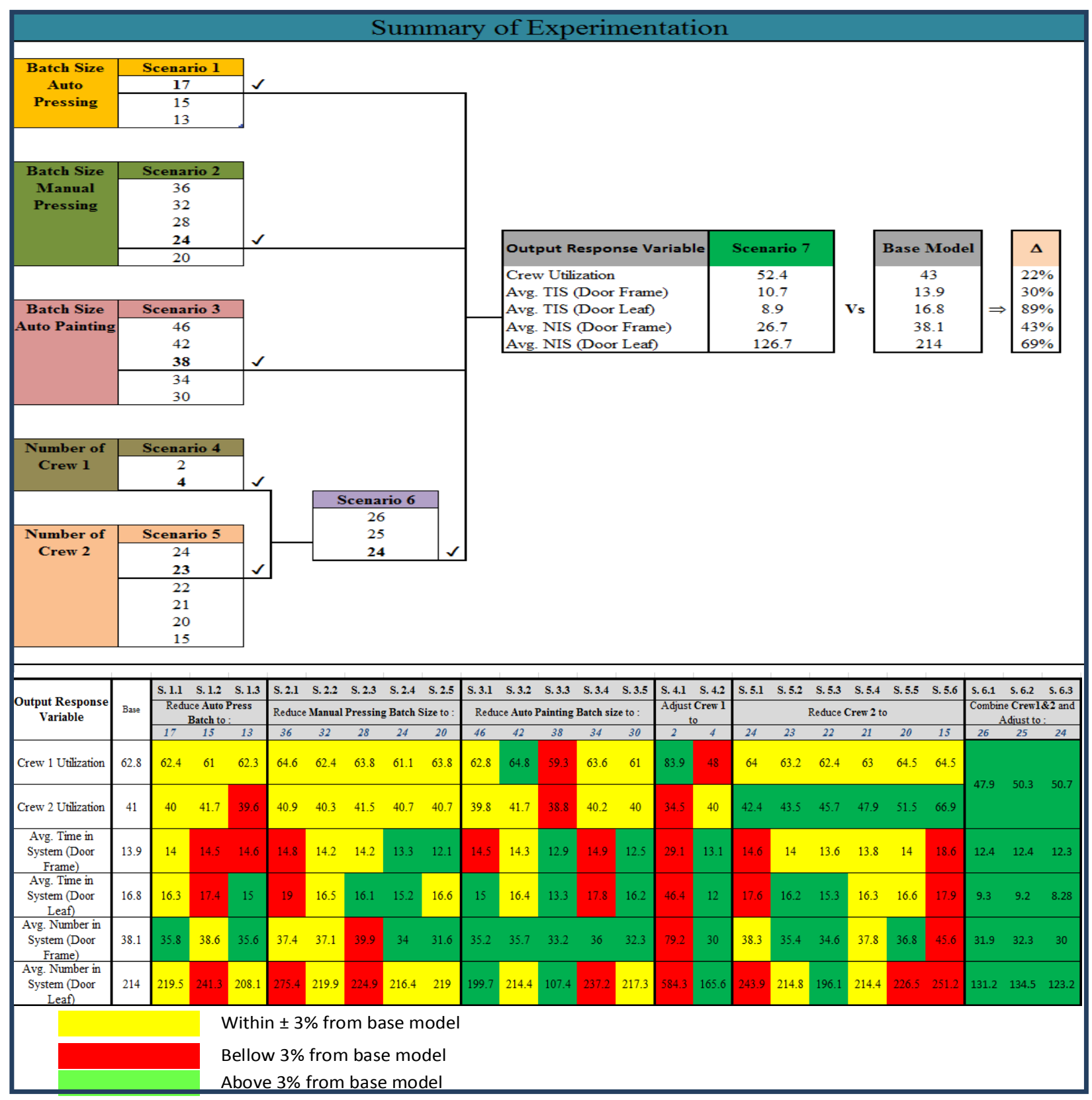

Figure 8. Summary of experimentation

The experimentation was done by running several scenarios, each with 25 replications and one-year simulation length. Seven scenarios were experimented and evaluated against the base scenario as follows:

- Base scenario: is the base model with current level of manpower (crew 1 and 2) and current batching size in "Automatic Pressing", "Manual Pressing", and "Auto Painting" servers.

- Scenario 1: is the scenario of changing the batching size in "Auto Pressing". These scenarios investigated batch reduction in Automatic Pressing server from 20 to 17, 15, and 13.

- Scenario 2: is the scenario of changing the batching size in "Manual Pressing". These scenarios investigated batch reduction in
“Manual Pressing” server from 40 to 36, 32, 28, 24, and 20.

- Scenario 3: is the scenario of changing the batching size in "Auto Painting". These scenarios investigated batch reduction in "Auto Painting” server from 50 to 46, 42, 38, 34, and 30.

- Scenario 4: is the scenario of adjusting the size of crew 1. These scenarios investigated the adjustment of number of crew 1 to 2 (reduced) and 4 (increased) workers.

- Scenario 5: is the scenario of reducing the size of crew 2. These scenarios investigated the possibility of reducing number of crew 2 from 25 to $24,23,22,21,20$, and 15 .

- Scenario 6: is the scenario of combining crew 1 and crew 2 while at the same time reducing the 
size of combined crew from 28 to 26,25 , and 24.

- Scenario 7: is the combination of scenarios 1 6 and meant as the final recommendation for the studied company.

Scenarios $1-6$ were experimented by changing the "input controlled variables" such as: Number of Crew 1, Number of Crew 2, Batch Size Auto Painting, Batch Size Auto Pressing, Batch Size Painting, and Batch Size Manual Pressing.

Scenario 7 is the final scenario combining the best results of what have been simulated in scenarios $1-6$. The complete results of all scenarios are shown in Figure 8.

\section{Conclusion}

The study is successful in making the required simulation model which helps the performance evaluation of the studied job shop fabrication lines.

From the base model, several scenarios were developed as means to make the final recommended scenario. For the studied company, scenario 7 can become their alternative for process improvement, by combining all the crew with multi-skill operators. Consequently, training or different recruitment scheme must be done. Other possible improvements are to reduce the batching size in 3 processes, which can reduce total time in system. All together, scenario 7 creates opportunity to increase crew utilization by $22 \%$, and improve total time in system for DL and DF to $89 \%$ and $30 \%$, respectively.

From the methodology point of view, simulation and Simio are proven to be attractive and suitable tools in evaluating a (medium) complex system such as that in the studied company. The model building and data collection are indeed time consuming and challenging. Nevertheless, they give merits in increasing evaluation fitness and accommodating real-life details into the analyses - which will be more difficult if using mathematical model.

The study poses some limitation due to lack of historical data and time constraints, upon which the following further study can be explored:

(1) Revisit and enhance the model once the studied company has captured sufficient historical performance to better validate the model.

(2) Add more details into the models, such as put all (and not only few) variables into random variables, including the travelling time into the operators (and not only to entity), etc.

(3) The study can be extended as a design tool to help the studied company determine other alternative production sequencing or calculate the capacity of fabrication system.

(4) The study can be extended to evaluate not only technical production parameters such as utilization or time in system, but also associated cost parameters.

\section{Acknowledgement}

The authors would like to thank Simio LLC. for granting the free education version of the Simio Simulation and Scheduling Software, which make this research possible.

\section{References}

1. Statistics Indonesia (BPS), Persentase Pengeluaran Rata-rata per Kapita Sebulan Menurut Kelompok Barang [Average Expenditure Percentage per Capita per Month Grouped by Goods], 2018, retrieved from https://www.bps.go.id/statictable/ 2009/06/15/937/persentase-pengeluaran-rata-rataper-kapita-sebulan-menurut-kelompok-barangindonesia-1999-2002-2016.html.

2. Salanto, F., Jakarta I Apartment, Colliers Quarterly, Q4 2016, Feb. 2017, retrieved from http://www.colliers.com//-/media/files/ marketresearch/apac/indonesia/q4-2016colliersquarterly-jakarta-apartment.pdf?la=en-GB.

3. Heizer, J. and Render, B., Operations Management: Sustainability and Supply Chain Management, $11^{\text {th }}$ ed., Pearson, Essex (England), 2014.

4. Raj, A.S.V., Mathew, J., Jose, P., and Sivan, G., Optimization of Cycle Time in an Assembly Line Balancing Problem, Procedia Technology, 25, 2016, pp. 1146-1153, doi: 10.1016/j.protcy.2016.08.231.

5. Xie, C. and Allen, T.T., Simulation and Experimental Design Methods for Job Shop Scheduling with Material Handling: A Survey, The International Journal of Advanced Manufacturing Technology, 80(1-4), Sep. 2015, pp. 233-234, doi: 10.1007/s00170-015-6981-x.

6. Kaylani, H. and Atieh, A.M., Simulation Approach to Enhance Production Scheduling Procedures at a Pharmaceutical Company with Large Product Mix, Procedia CIRP, 41, 2016, pp. 411-416, doi: 10.1016/j.procir.2015.12.072.

7. Banks, J., Introduction to Simulation, Proc. of the 1999 Winter Simulation Conference (Eds.: Farrington, P.A., Nembhard, H.B., Sturrock, D.T., and Evans, G.W.), Phoenix (AZ, USA), Dec. 1999, pp. 7-13, doi: 10.1145/324138.324142.

8. Roessler, M.P., Riemer, J., and Mueller, M., Decision Support for Choosing an Appropriate Simulation Method for Dynamic Material Flow Analysis, Journal of Industrial and Intelligent Information, 3(4), Dec. 2015, pp. 337-341, doi: 10.12720/jiii.3.4.337-341.

9. Hassan, S.A. and Abdelsalam, H.M., An Exploratory Simulation Model for Contraception Methods' Supply Chain in Egypt, Procedia Technology, 16, 2014, pp. 1403-1410, doi: 10.1016/j.protcy.2014.10.159.

10. Semanco, P. and Marton, D., Simulation Tools Evaluation Using Theoretical Manufacturing Model, Acta Polytechnica Hungarica, 10(2), 2013, pp. 193204. 
11. Zupan, H. and Herakovic, N., Production Line Balancing with Discrete Event Simulation: A Case Study, IFAC-PapersOnLine, 48(3), 2015, pp. 23052311, doi: 10.1016/j.ifacol.2015.06.431.

12. Pröpster, M., März, L., Reinhart, G., and Intra, C., Validation of Line Balancing by Simulation of Workforce Flexibility, Procedia CIRP, 33, 2015, pp. 93-98, doi: 10.1016/j.procir.2015.06.018.

13. Law, A.M. and McComas, M.G., Simulation of Manufacturing Systems, Proc. of the 1997 Winter Simulation Conference (Eds.: Andradóttir, S., Healy, K.J., Withers, D.H., and Nelson, B.L.), Atlanta (GA, USA), Dec. 1997, pp. 86-89, doi: 10.1109/WSC.1997.640382.

14. Sutalaksana, I.Z., Anggawisastra R., and Tjakraatmadja, J.H., Teknik Perancangan Sistem Kerja [Techniques for Work Systems Design], $2^{\text {nd }}$ ed., ITB Bandung, 2012.

15. Ahmad, I., Hussain, A., Maqsood, S., and Khattak, S.B., Internal Benchmarking in Discrete Manufacturing through Simulation, Technical Journal UET Taxila, 20(II-S), 2015, pp. 177-183.

16. Banks, J., Carson, J.S., Nelson, B.L., and Nicol, D.M., Discrete-Event System Simulation, $5^{\text {th }}$ ed.,
Prentice Hall International Series in Industrial and Systems Engineering, 2010.

17. Luo, L., Liu, H., Liao, H., Tang, S., Shi, Y., and Guo, H., Discrete Event Simulation Models for CT Examination Queuing in West China Hospital, Computational and Mathematical Methods in Medicine, 2016, article ID: 2731675, doi: 10.1155/ 2016/2731675.

18. Lima, A.D.P., de Mascarenhas, F.W., and Frazzon, E.M., Simulation-Based Planning and Control of Transport Flows in Port Logistic Systems., Mathematical Problems in Engineering, 2015, article ID: 862635, doi: 10.1155/2015/862635.

19. Cataldo, A., Taisch, M., and Stahl, B., Modelling, Simulation and Evaluation of Energy Consumptions for a Manufacturing Production Line, Proc. of $39^{\text {th }}$ Annual Conference of the IEEE Industrial Electronics Society (IECON), Vienna (Austria), Nov. 2013, pp. 7537-7542, doi: 10.1109/IECON. 2013.6700388.

20. Simio, Simio Reference Guide, Version 8, Simio LLC., 2015. 